\title{
PERANCANGAN DAN PEMBUATAN MOBILE LEARNING INTERAKTIF BERBASIS ANDROID DENGAN METODE PERSONAL EXTREME PROGRAMMING
}

\author{
Hidayat Rizal ${ }^{1}$, Satriyo Adhy ${ }^{2}$, Panji Wisnu Wirawan ${ }^{3}$ \\ Jurusan Ilmu Komputer/ Informatika Universitas Diponegoro \\ Email : rivaldayat@gmail.com ${ }^{1}$, satriyo@undip.ac.id ${ }^{2}, \underline{\text { maspanji@undip.ac.id }}{ }^{3}$
}

\begin{abstract}
Mobile Learning ( M - Learning ) is the learning by using mobile devices, regardless of time and place. M-Learning has the constraint that M-Learning users must connect to the internet to be able to get the learning content. With the Android device, that could be implanted a native application inside, allowing the M - Learning content stored on the device. This study examines how the native application can be developed with Personal Extreme Programming method. In addition, this study reinforces previous research that E-Learning can be expanded ability to be M-Learning. As an outcome of this study is a MLearning application that utilizes E-Learning that has existed , in which $\mathrm{M}$ - Learning applications that have some capability of E - Learning that capture and store content on mobile devices, so that the content is not required to access the internet connection .
\end{abstract}

Keywords : M-Learning, Android, Personal Extreme Programming

\section{PENDAHULUAN}

Teknologi perangkat bergerak yang sudah sedemikian cepat perkembangannya dapat dimanfaatkan dalam berbagai bidang kehidupan, salah satu contohnya adalah pada bidang pendidikan. Penggunaan perangkat bergerak dalam aktivitas pembelajaran disebut dengan MLearning. M-Learning dianggap sebagai suplemen untuk E-Learning tradisional dimana mobilitas adalah nilai tambah bagi para peserta didik. Data kursus atau perkuliahan dapat dimanfaatkan sehingga tidak perlu membuat sistem M-Learning terpisah dari E-Learning[8].

Berdasar latar belakang tersebut, permasalahan yang timbul adalah kebutuhan apa saja yang sesuai untuk diterapkan pada pengembangan M-Learning serta bagaimana data pada E-Learning dapat terintegrasi dengan baik sesuai dengan request dari client M-Learning. Penelitian ini bertujuan untuk merancang dan membuat aplikasi client M-Learning berbasis Android dengan metode Personal Extreme Programming. Aplikasi client diimplementasikan dengan native application berbasis Android karena Android menjadi platform dengan pengguna terbanyak dari 2009 hingga 2012[3]. Selain itu adanya kemampuan penyimpanan data serta fitur yang interaktif menjadi nilai tambah pengembangan aplikasi.
Aplikasi yang dihasilkan diharapkan dapat memberi manfaat bagi pengguna khususnya mahasiswa dalam mengolah data serta memperoleh informasi tentang perkuliahan yang lebih cepat dan fleksibel menggunakan perangkat bergerak berbasis Android.

\section{TINJAUAN PUSTAKA}

\section{M-Learning}

Teknologi perangkat genggam nirkabel yang menggunakan jaringan telepon dan internet dalam memfasilitasi, mendukung, meningkatkan serta memperluas jangkauan belajar mengajar dinamakan M- Learning[7].

\section{Interaktif}

Media interaktif adalah integrasi media digital termasuk kombinasi teks elektronik, grafis, gambar bergerak, dan suara menjadi terstruktur dalam lingkungan komputerisasi digital yang memungkinkan orang untuk berinteraksi dengan data untuk tujuan tertentu. Lingkungan digital dapat mencakup internet, telekomunikasi dan televisi digital interaktif[5].

\section{Personal Extreme Programming}

Practices XP dapat diterapkan untuk menangani situasi proses pengembangan 
perangkat lunak dengan pemrogram tunggal, yang kemudian dinamakan dengan metodologi Personal Extreme Programming[1].

Practice PXP meliputi The Planning Game, Test Driven Development, Small Release, Simple Design, Refactoring, Continues Integration, OnSite Customer, Coding Standard. Fase proses PXP ditunjukkan pada gambar 1.

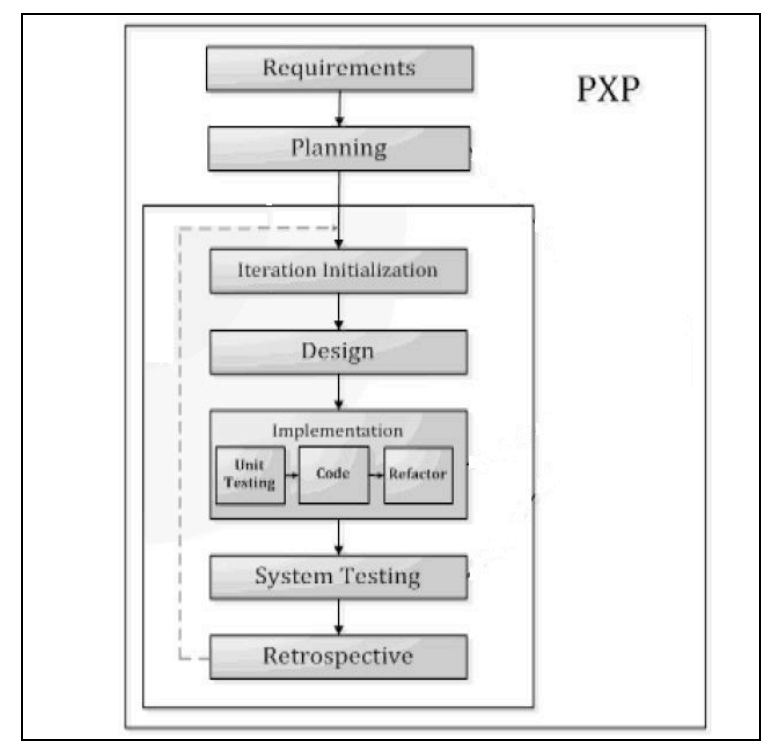

Gambar 1. Fase Proses PXP

Fase proses tersebut mengacu pada penelitian Dzhurov (2009) yang berjudul "Personal Extreme Programming-An Agile Process for Autonomous Developers". Tahap Requirements mendifinisikan segala kebutuhan sistem yang dikembangkan. Menentukan estimasi stories, prioritas dan iterasi yang dibutuhkan dalam pengembangan sistem dilaksanakan pada tahap planning. Proses implementasi dilakukan dengan metode Test Driven Development (TDD)[4].

User Story dan Story Card

Penulisan stories dapat dituliskan dengan susunan "As a [role] I can [function] so that [rationale]." Penulisan story yang baik bersifat independent, negotiable, valuable user customer, estimatable, small dan testable[2].

Stories ditulis tidak untuk menyatakan sebuah kontrak atau kesepakatan terhadap kebutuhan perangkat lunak yang harus diimplementasikan. Story Cards mendiskripsikan fungsionalitas singkat dari percakapan antara pelanggan dan tim pengembangan. Story cards menjadi media untuk menuliskan story dan acceptance criteria dari tiap fungsional sistem yang diinginkan oleh pengguna.

\section{Android}

Menurut Meier (2009), Android adalah sebuah software stack bersifat open source yang mencakup sistem operasi, middleware, dan key applications beserta sekumpulan Application Programming Interface (API) untuk merancang sebuah aplikasi mobile dengan menggunakan bahasa pemrograman Java. Aplikasi berbasis android dapat diciptakan, dikembangkan secara bebas serta dapat dengan mudah diunduh dan digunakan sesuai kebutuhan pengguna.

\section{REQUIREMENT DAN RELEASE PLAN}

Bagian ini akan membahas fase awal dari proses PXP, yaitu requirement dan planning. Pada awal requirement, akan diidentifikasi pengguna sistem, dilanjutkan dengan pembentukan arsitektur sistem dan diakhiri dengan pembentukan fungsionalitas sistem secara keseluruhan.

Arsitektur pembelajaran M-Learning dapat ditunjukkan pada Gambar 2. Pengguna pada sistem M-Learning terdiri dari Dosen, Mahasiswa, dan Administrator. Dosen dan Mahasiswa dapat mengakses sumber daya pembelajaran melalui $P C$ atau perangkat bergerak. Sistem yang dikembangkan pada penelitan ini bernama Mobile Learning Interaktif (MLI). Sistem terbagi menjadi dua buah subsistem yaitu :

1) MLI-server.

2) MLI-client.

MLI-server menggunakan aplikasi database E-Learning Moodle berbasis web yang dapat diakses oleh Admin, Dosen, maupun Mahasiswa melalui browser. MLI-server memiliki layer MLearning service yang fungsinya untuk menerima request dan memberikan reponse kepada client sehingga data pada MLI-server dan MLI-client dapat terintegrasi dengan baik. 


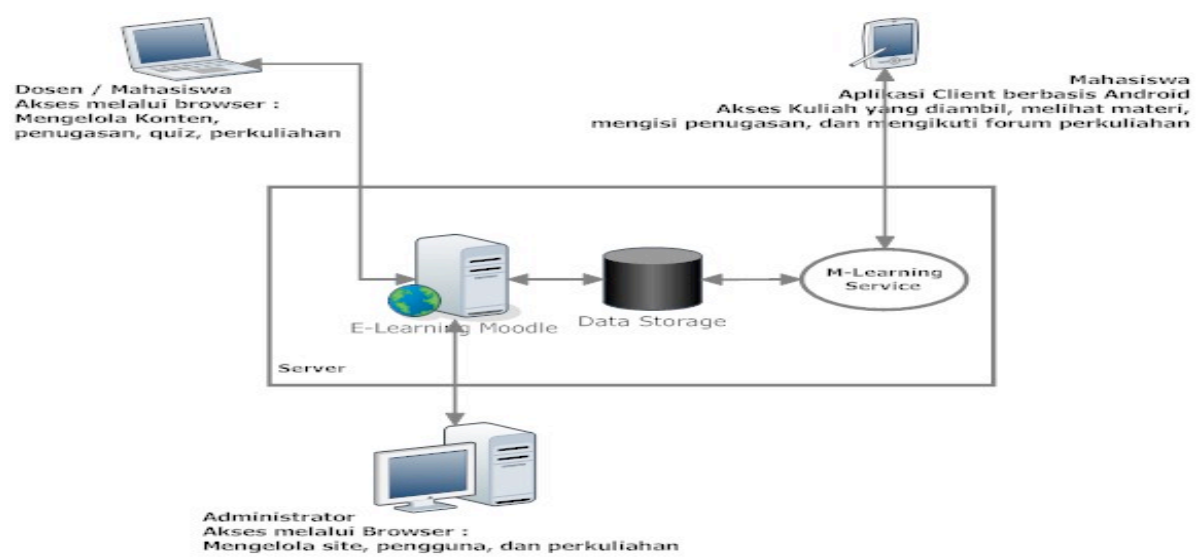

Gambar 2. Arsitektur M-Learning yang Dibangun

MLI client akan dirancang dengan mengacu pada pedagogy M-Learning yaitu Course Location, Class Experience, Class Materials, dan Assignments. Fungsionalitas sistem utama pada MLI-client ditunjukkan pada tabel 1.

Tabel 1. Fungsionalitas Sistem MLI-client

\begin{tabular}{|l|l|}
\hline Pedagogy & MLI-client \\
\hline $\begin{array}{l}\text { Course } \\
\text { Location }\end{array}$ & $\begin{array}{l}\text { M-Learning diimplementasikan } \\
\text { pada sebuah native application } \\
\text { pada perangkat bergerak }\end{array}$ \\
\hline $\begin{array}{l}\text { Class } \\
\text { Materials }\end{array}$ & $\begin{array}{l}\text { Menampilkan daftar kuliah dan } \\
\text { materi yang sesui }\end{array}$ \\
\hline $\begin{array}{l}\text { Class } \\
\text { Experience }\end{array}$ & $\begin{array}{l}\text { Memberikan pesan cepat atau } \\
\text { notifikasi jika ada tugas baru dari } \\
\text { Dosen. }\end{array}$ \\
\hline Assignments & $\begin{array}{l}\text { Menyediakan fasilitas penugasan } \\
\text { pada tiap kuliah }\end{array}$ \\
\hline
\end{tabular}

Tabel 2 menunjukkan Daftar Release Planning sistem Mobile Learning Interaktif berbasis Android yang terdiri dari 4 iterasi.

Tabel 2. Daftar Release Planning

\begin{tabular}{|l|c|l|c|}
\hline No. & $\begin{array}{c}\text { Kode } \\
\text { Story }\end{array}$ & \multicolumn{1}{|c|}{ Deskripsi } & $\begin{array}{l}\text { Estimasi } \\
\text { (dalam } \\
\text { hari) }\end{array}$ \\
\hline Iteration - 1 \\
\hline 1. & US-01 & $\begin{array}{l}\text { Melakukan Login } \\
\text { sistem. }\end{array}$ & 2 \\
\hline 2. & US-02 & $\begin{array}{l}\text { Menampilkan } \\
\text { daftar mata } \\
\text { kuliah yang } \\
\text { diambil. }\end{array}$ & 2 \\
\hline
\end{tabular}

\begin{tabular}{|c|c|c|c|}
\hline No. & $\begin{array}{l}\text { Kode } \\
\text { Story }\end{array}$ & Deskripsi & $\begin{array}{l}\text { Estimasi } \\
\text { (dalam } \\
\text { hari) }\end{array}$ \\
\hline 3. & US-03 & $\begin{array}{l}\text { Menampilkan } \\
\text { daftar materi tiap } \\
\text { mata kuliah yang } \\
\text { diambil. }\end{array}$ & 2 \\
\hline 4. & US-05 & $\begin{array}{l}\text { Menampilkan } \\
\text { daftar unduh } \\
\text { materi tiap mata } \\
\text { kuliah } \\
\text { diambil. }\end{array}$ & 2 \\
\hline \multicolumn{3}{|c|}{ Velocity } & 8 \\
\hline \multicolumn{4}{|c|}{ Iteration - 2} \\
\hline 1. & US-07 & $\begin{array}{l}\text { Menampilkan } \\
\text { daftar tugas } \\
\text { kuliah kuliah. }\end{array}$ & 2 \\
\hline 2. & US-04 & $\begin{array}{l}\text { Melihat detail } \\
\text { materi kuliah. }\end{array}$ & 1 \\
\hline 3. & US-06 & $\begin{array}{lr}\text { Melihat } & \text { detail } \\
\text { unduh } & \text { materi } \\
\text { kuliah } & \\
\end{array}$ & 1 \\
\hline 4. & US-08 & $\begin{array}{l}\text { Melihat detail } \\
\text { tugas kuliah. }\end{array}$ & 1 \\
\hline 5. & US-09 & $\begin{array}{l}\text { Mengirim } \\
\text { jawaban tugas } \\
\text { kuliah. }\end{array}$ & 1 \\
\hline 6. & US-10 & $\begin{array}{l}\text { Mengubah } \\
\text { jawaban tugas } \\
\text { kuliah. }\end{array}$ & 1 \\
\hline 7. & US-11 & $\begin{array}{l}\text { Melihat nilai } \\
\text { tugas kuliah. }\end{array}$ & 1 \\
\hline \multicolumn{3}{|c|}{ Velocity } & 8 \\
\hline \multicolumn{4}{|c|}{ Iteration - 3} \\
\hline 1. & US-12 & $\begin{array}{l}\text { Melihat daftar } \\
\text { forum. }\end{array}$ & 1 \\
\hline
\end{tabular}




\begin{tabular}{|l|l|l|c|}
\hline No. & $\begin{array}{c}\text { Kode } \\
\text { Story }\end{array}$ & \multicolumn{1}{|c|}{ Deskripsi } & $\begin{array}{c}\text { Estimasi } \\
\text { (dalam } \\
\text { hari) }\end{array}$ \\
\hline 2. & US-13 & $\begin{array}{l}\text { Melihat diskusi } \\
\text { forum }\end{array}$ & 1 \\
\hline 3. & US-14 & $\begin{array}{l}\text { Menambah } \\
\text { diskusi forum }\end{array}$ & 1 \\
\hline 4. & US-15 & $\begin{array}{l}\text { Melihat komentar } \\
\text { diskusi forum }\end{array}$ & 1 \\
\hline 6. & US-17 & $\begin{array}{l}\text { Mendapatkan } \\
\text { pesan cepat }\end{array}$ & 2 \\
\hline 7. & US-18 & $\begin{array}{l}\text { Mengubah } \\
\text { Password akun }\end{array}$ & 2 \\
\hline \multicolumn{2}{|l|}{ Velocity } \\
\hline \multicolumn{2}{|l|}{ Iteration-4 } & $\begin{array}{l}\text { Menambah } \\
\text { komentar diskusi } \\
\text { forum }\end{array}$ & 1 \\
\hline & US-16 & 1 \\
\hline \multicolumn{2}{|l|}{ Velocity }
\end{tabular}

\section{PEMBAHASAN}

Pada bagian pembahasan, akan dideskripsikan bagian inti dari PXP. Diawali dari iterasi awal (initial iteration) sampai dengan pengujian. Untuk meringkas penulisan, hanya akan disajikan bagaimana mengimplementasikan user story US-01.

\section{Initial Iteration}

Konfigurasi dan pembuatan M-Learning service dapat selesai dalam waktu 8 hari. Sesuai dengan perencanaan pada release planning yang telah disusun sebelumnya, apabila velocity bernilai 8 maka untuk menyelesaikan story points dengan jumlah 25 dibutuhkan 4 kali iterasi

\section{Implementasi}

Siklus implementasi pada PXP adalah digunakannya TDD Acceptance Test yang diimplementasikan dengan Acceptance Test Story (Tabel 3), Unit Test Story (Tabel 4) dan implementasinya (Tabel 5). Siklus tersebut diawali dari pembentukan story beserta acceptance test-nya, kemudian dilanjutkan dengan pengujian unit (unit testing), implementasi kode dan refactoring (jika diperlukan).
Tabel 3. Acceptance Test Story US-01 Acceptance Test Story US-01

1) Memeriksa validasi data username dan password pada server database

2) Menyimpan data pengguna pada SQLite database

3) Proses Login tidak dilakukan apabila data username dan id seorang Mahasiswa telah tersimpan dalam aplikasi

Tabel 4. Unit Test Story US-01

\begin{tabular}{|c|}
\hline Kutipan Kode Unit Test Story US-01 \\
\hline $\begin{array}{l}\text { public void testGetCekUser() \{ } \\
\text { json = loginparser.getCekPengguna(username, } \\
\text { password); }\end{array}$ \\
\hline 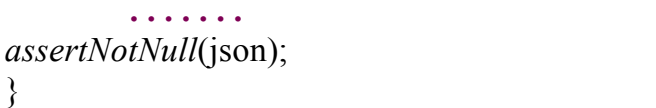 \\
\hline
\end{tabular}

\section{Tabel 5. Implementasi Test Story US-01}

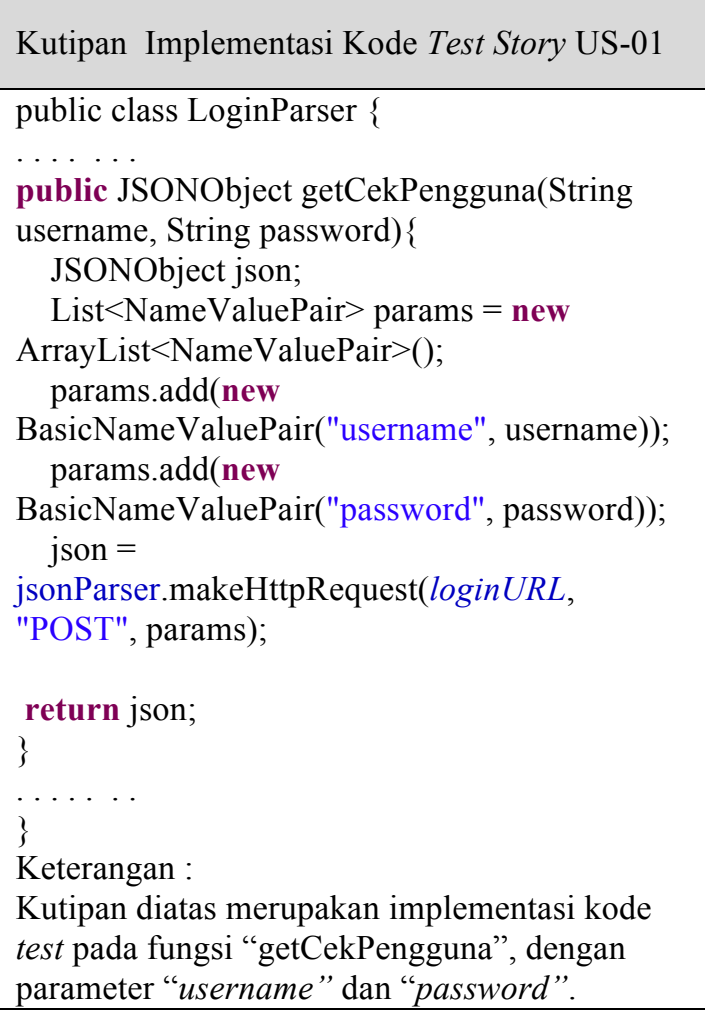

Ketika implementasi kode telah memenuhi acceptance criteria, tahapan berikutnya adalah dokumentasi desain yang dibentuk dari hasil implementasi. Berbeda dengan pengembangan perangkat lunak menggunakan metode waterfall, 
pengembangan perangkat lunak metode PXP menyusun desain ketika implementasi telah teruji, berdasarkan pengujian unit.

Desain Sistem untuk Story US-01 ditunjukkan pada tabel 6. Desain sistem terdiri dari class diagram, sequence diagram, dan desain antarmuka sistem.

Tabel 6. Desain Sistem Story US-01

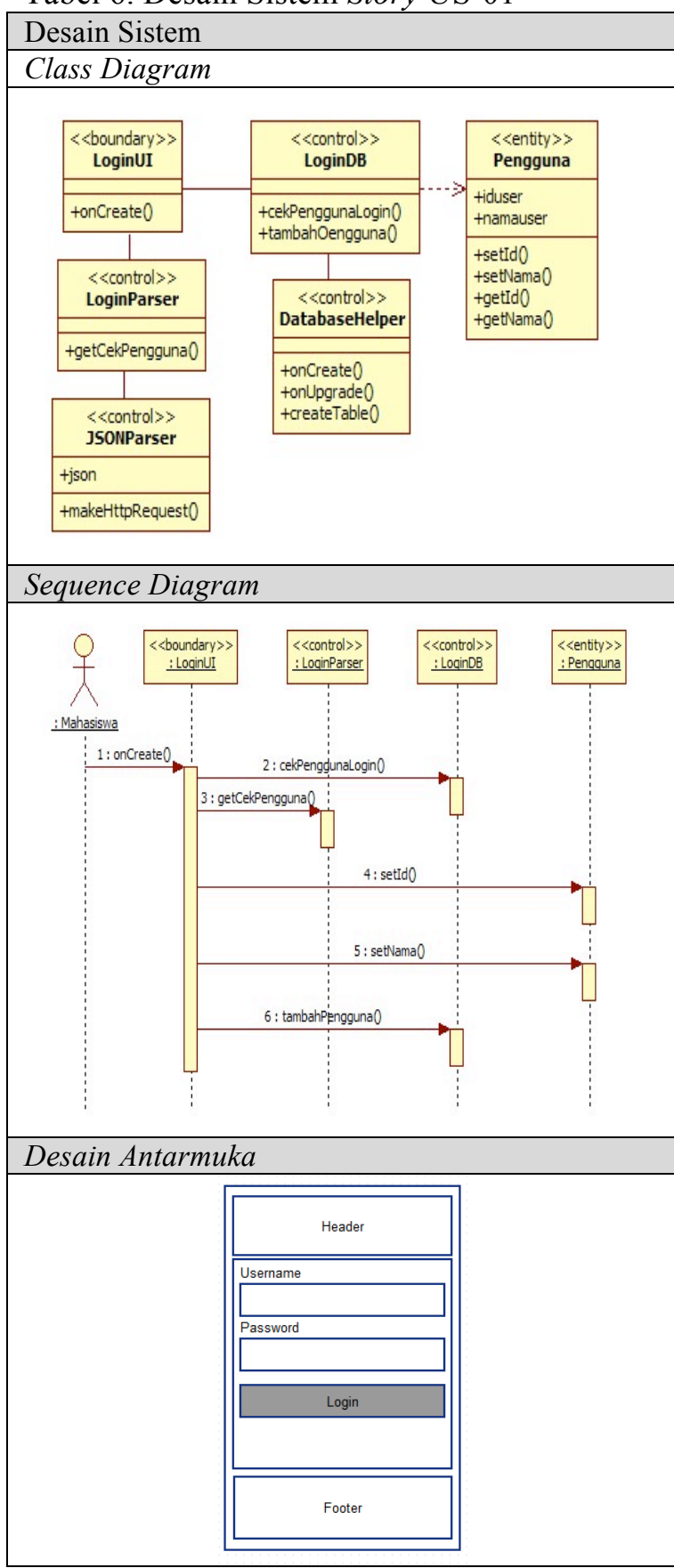

Implementasi antarmuka pada Story Login System yang ditunjukkan pada gambar 3 .

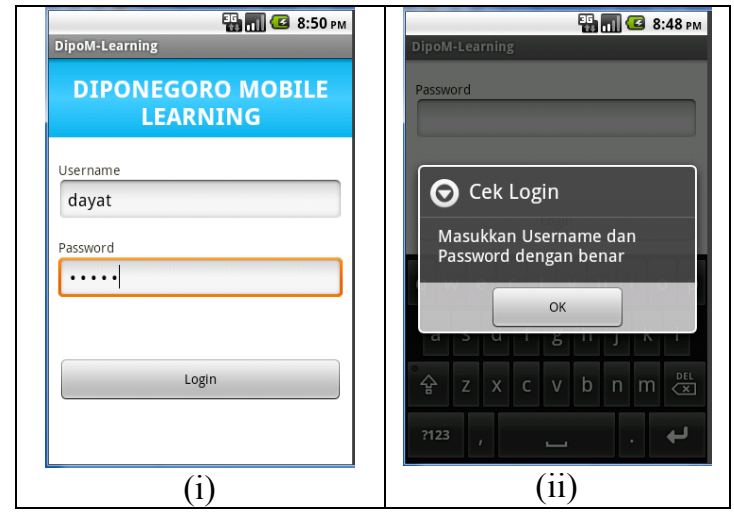

Gambar 3. Antarmuka Login System

\subsection{Iteration Burdown Chart}

Progress implementasi story pada keseluruhan iterasi. Gambar 4 (i) menunjukkan burdown chart pada iteration planning yang diususun. Gambar 4 (ii) menunjukkan bahwa terjadi perubahan iterasi pada perancangan dan pembuatan M-Learning Interaktif yang seharusnya terdapat 4 iterasi untuk menyelesaikan 25 story points. Iterasi ke -3 terjadi perubahan velocity karena terdapat penambahan story points yang berasal dari story pada iterasi ke - 4. M-Learning dapat diselesaikan lebih cepat dari rencana yang disusun dengan iterasi yang lebih pendek yaitu 3 iterasi dalam waktu 6 minggu.

\section{KESIMPULAN}

Kesimpulan yang dapat diambil dalam penelitian ini adalah dihasilkan sebuah aplikasi Mobile Learning ( $\mathrm{M}$ - Learning) Interaktif berbasis Android yang dikembangkan dengan metode Personal Extreme Programming. Layanan penghubung M-Learning Service dibangun untuk mengintegrasikan sumber daya pada aplikasi client dengan server E-Learning.

Aplikasi client M-Learning memiliki fitur untuk menampilkan informasi mata kuliah yang diambil, informasi materi tiap kuliah, informasi materi unduh file, informasi penugasan, dan informasi forum serta menambah diskusi forum. Penerapan metode PXP memberikan kemudahan dalam memperkirakan kemampuan pengembangan perangkat lunak yang 
dikembangkan. Hal tersebut ditunjukkan dengan burndown chart yang dihasilkan.

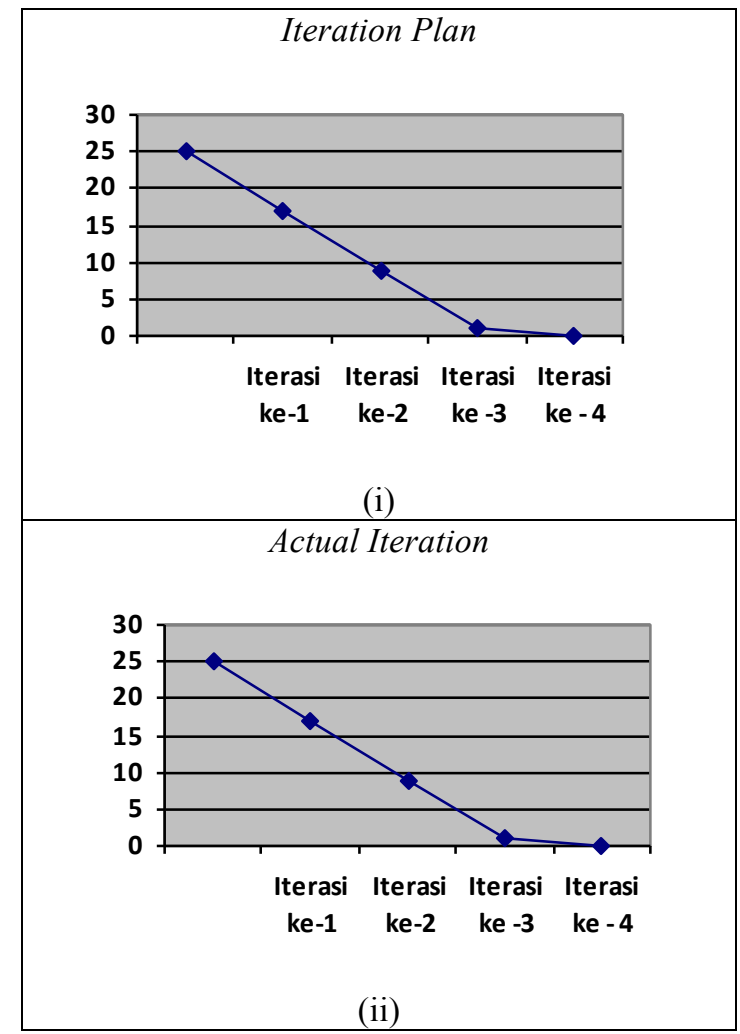

Gambar 4. Iteration Burdown Chart

\section{DAFTAR PUSTAKA}

[1] Agarwal R. dan Umphress D., 2008, "Extreme Programming for a Single Person Team", Computer Science \& Software Engineering 107 Dunstan Hall Auburn University.

[2] Cohn M., 2004, "User Stories Applied : For Agile Software Development", Adison Wesley.

[3] Develop Economic, 2013, "Android Rises to Smartphone Domination : Smartphone OS Sales (2009-2012)

[4] Dzhurov Y.,2009, "Personal Extreme Programming - An Agile Process for Autonomous Developers", Proceedings of International Conference on SOFTWARE, SERVICES \& SEMANTIC TECHNOLOGIES, Sofia, Bulgaria, ISBN 978-954-9526-62-2.
[5] England E. dan Finney A., 2011, "Interactive Media-What's that? Who's involved", ATSF White Paper-Interactive Media UK-2002/2011 ATSF,( http:// www.atsf.co.uk/atsf/interactive_media.pdf).

[6] Meier R., 2009, "Professional Android Application Development", Indianapolis, Indiana, United States of America: Wiley Publishing, Inc.

[7] Schofield C.P., West T., dan Taylor E., 2011, "Going Mobile In Executive Education", Ashridge, Berkhamsted.

[8] Wirawan, Panji W., 2012, "Pengembangan Kemampuan E-Learning Berbasis Web Ke Dalam M-Learning", Jurnal Masyarakat Informatika, Volume 2 ( Nomor 4, ISSN 2086-4930), Hlm. 21-26. 